\title{
AQUATIC AND ATMOSPHERIC SIMULATION
}

\author{
J. B. Knox \\ D. M. Hardy
}

C. A. Sherman

June 18, 1973

Prepared for U.S. Atomic Energy' Commission under contract No. W-7405-Eng-48

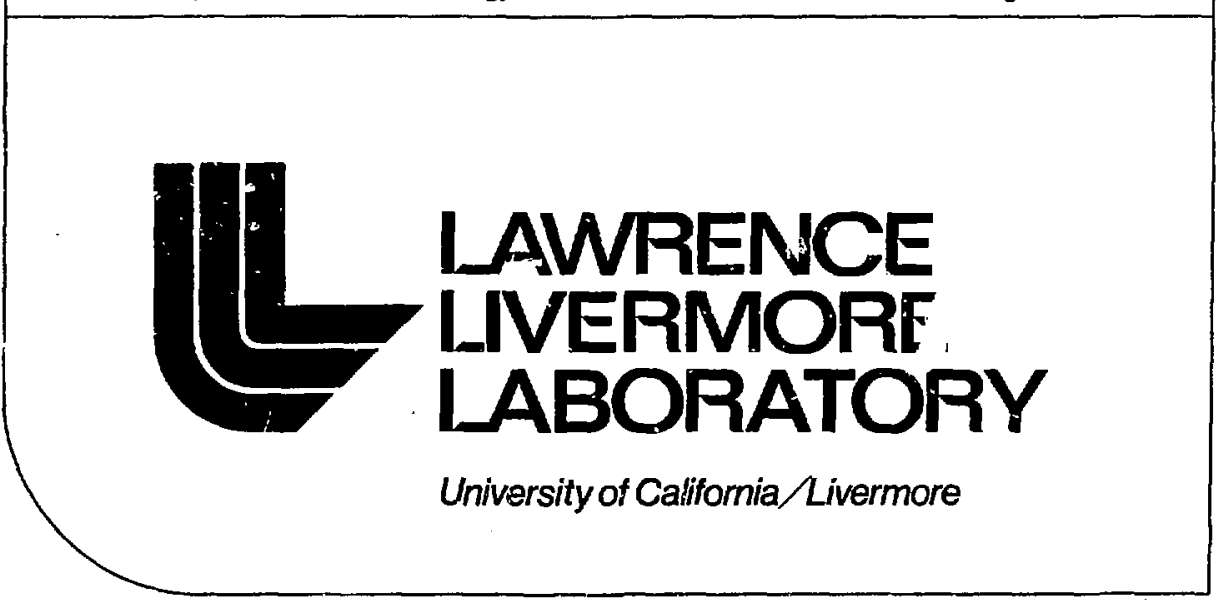

MASTER 
Notsce:

"This seport was propyrel as an scermm of wert sponored hy

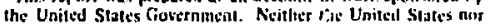
the Uniced Siales Alomic lineray Conumssion, Bhar any ar thetr criployes, nor any of their contracluts, subecuntraters, or thew

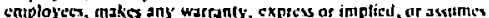

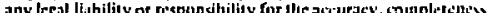
any lepalis

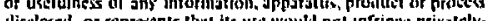
disclosed, or reprexents thet it owned rights."

Printed in the United States of America Available from

National Technical Information Service U.S. Department of Commerce 5285 Port Royal Road Springfield, Virginia 32151

Price: Printed Copy $\$$; Microfiche $\$ 0.95$

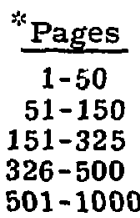

NTIS

Selling Price

$\$ 4.00$

$\$ 5.45$

$\$ 7.60$

326-500

$\$ 10.60$

$\$ 13.60$ 
TID-4500, UC-32

Mathematics and

Computers

\title{
노
}

LAWFENCE LNEFWORE LAEORATORY

Iniversity of Callomia/Lwermon, Cavornia/94550

UCRL-51405

\section{AQUATIC AND ATMOSPHERIC SIMULATION}

\author{
J. B. Knox \\ D. A. Hardy \\ C. 1 Sherman
}

MS. date: June 18, 1973

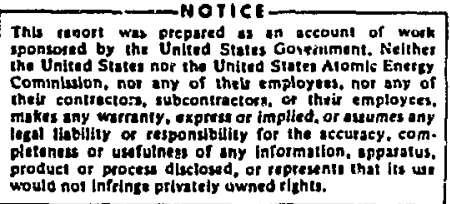

This revort was prepared as in eccouns of work sponsored by the Unlted States Govesument. Neither the United Ststes nor the United States Alomle Enetry Cominswi, nar any of the employtes, nor any af

mhkes any wirning, exprrss or implied, or auumes any

would not Infringe privately uwned rlehts. 


\title{
AQUATIC AND ATMOSPHERIC SIMULATION
}

\begin{abstract}
During the last few years, the Lawrence Livermore Laboratory has been involved in regional and extended scale air pollution modeling. Several numerical models have been developed for atmospheric studies. These models contain

methods of solution that are transferable to significant unsolved problems in water pollution. This transferable experience is discussed and illuetrated in terms of regional scale sediment transport problems.
\end{abstract}

\section{Introduction}

Environmental pollution is a widespread and persistent problem. Models of the spatial and temporal pvolution of pollutants - from emission, through transport and transformation, to deposition-are becoming increasingly important to public and private groups concerned with environmental planning.
Atmospheric modeling at the Lawrence Livermcre Laboratory has succeeded in tracing air pollutants from source to receptor. The same kind of modeling can be applied to water pollution problems, particularly to such problems as channel dredging, waste discharges and general water quality.

\section{The Role of Numerical Simulation Models}

A numerical simulation model, whether it is of an atmospheric or aquatic system. should be an interpretative bridge which permits a description of the distribution of a pollutant from its source to receptors of interest. The simulation model should comprise a physically and chemically consistent description of the temporalspatial pollutant distribution, including the effects of production, transformation, and removal mechanisms that occur dur- ing the advective-diffusive transport of the pollutant. Once the history of a pollutant can be predicted at a receptor, there are then many potential applications of that information. For example, time integrated pollution exposures in the atmosphere, or analogously, integrated aquatic intakes can be estimated. Numerous other applications are possible, the choice depending largely on the needs of the user. 


\section{Aquatic Systems Sirnulation}

Staff members of the Laboratory have made several studies of aquatic systems; some of the most pertinerit studies are

\section{- WATER WAVE PHENOMENA ASSOCIATED WITH TECTONIC DISPLACEMENTS}

Water waves generated by tectonic displacements have been numerically simulat. I with a two-dimensional Marker and Cell code. The simulation has been validated by hydraulic tank studies with generally good reeults. 1 The code has been applied to the calculation of water waves produced by either explosive sources beneath the ocean floor or by fault displacements.

\section{- NUMERICAL SIMULATION OF ION-EXCHANGE COLUMNS}

Plilse shape and effluent isotopic time history have been numerically simulated for one-dimensional ion-exchange colimns wherein the matrix size, the isotope, the isotope distribution coefficient, and the column length and shape were variables. ${ }^{2}$

- TWO-DIMENSIONAL, TWOPHASE FLOW IN HETEROGENEOUS POROUS MEDIA

A numerical aimulation model for the calculation of two-phase transient flow in confined heterogeneous porous medla has been developed to evaluate gas well production under a variety of natural or altered conditions. 3
- OCEANIC DIFFusion IN THE MIXED LA YER

The Laboratory's Lagrangian large cloud diffusion code has been applied to the transport and diffusion in the oceanic mixed layer of a large pulse of tritiatec. water vapor which, under certain conditions, might be injected into the surface ocean water from a nuclear debris cloud. The code is based on mean ocean current information and estimates of the rate of energy dissipation (which are necessary for preacription of the horizontal eddy diffusivities). The code was used to estimate the timc and the range at which the aquatic pollutant concentrations reached recommended maximum permissible concentrations. ${ }^{4}$ Although events of this type have not been conducted, the estimaies are ciose to those of similarity theory. 5

\section{- ANOMALOUS GROUNDWATER MOUNDS ASSOCLATED WITH UNDERGROUND NUCLEAR DETONATIONS}

A few underground nuclear explosives tests in the mid 1960's showed that an anomalous groundwater mound may be created when the nuclear explosive is detonated near or below the water table. The major mechanism for the mound development is thought to be the compaction of the nearly saturated rock that surrounds the explosion. A numerical simulation model has been developed to calculate the time development of the anomalous mound and its associated now regimes. The model was compared to well histories and the role which this mound flow regime plays in geohydrologlcal safety considerations was discussed. ${ }^{6}$ 


\section{Atmospheric Modeling Experience Transferable to Aquatic Systems}

Numerous models were developed at the Laboratory for major atmospheric simulation studies. In addition to the development of important specialized models, the combination of several such models for the purpose of simulating complex systems were required. Differences between aquatic and atmospheric systems are apparent; the fundamental equations of fluid mechanics are, however. applicable in both cases and important processes such as diffusion and deposition have analoge in either system. Atmospheric modeling efforts at the Laboratory have led to the development of at least three numerical capabilities that are transferable to aquatic systems simulation

- a hybrid Lagrangian-Eulerian transport-diffusion code for accurately simulating three-dimensional pollutant distributions under sich scmplex conditions as transient stratified shear flow.

- a meteorological suiomodel for determining a mesoscale mass-consistent wind field suitable as input to a regional air pollution modei.

- a multibox regional air pollution model initialty verified for the San Francisco Bay Area.

A summary of these topics is given below?

\section{ATMOSPHEFIC DIFFUSION CODE}

We have developed a hybrid LagrangianEulerian three-dimensional particle diffusion code called ADPIC. It is used to calculate the distribution of pollutants under many difficult regional scale meteor- ological conditions, including near zero winds and transient stratified shear flow with complex surface boundaries. ${ }^{8}$ For a given time- and space-dependent wind-advection field, the code uses finite difference inethods to solve the threedimensional advection-diffusion equation in its conservative form using the pseudovelocity technique. The pollutant distribution is represented statistically by Lagrangian marker particles that are transported within the Eulerian grid. whose shape in space is determined by the surface topography. The present version of ADPIC allows the grid to travel with the moving cloud center and to expand automatically for purposes of minimizing calculational time while at the same time retaining necessary resolution. For fixed continuous point source applications, the source point is fixed and the Lagrangian particles are transported through the Eulerian mesh. The timeand space-dependent regional wind field must either be known or provided by a suitable model external to ADPIC; an essential requirement for the specified wind field is that it be free of false divergences.

Verification studies of ADPIC compare ADPIC solutions to Gaussian plume solutions for steady-state unidirectional flow and to analytic solutions for puff diffusion in steady-state shear flow. ${ }^{9}$ Figure 1 shows the ADPIC particle display of the pollutant distribution for this latter case. Figures 2 and 3 show the profiles in the $x y$ and $x z$ planes, respectively. These results definitively illustrate the chlef advantage of using a hybrid 


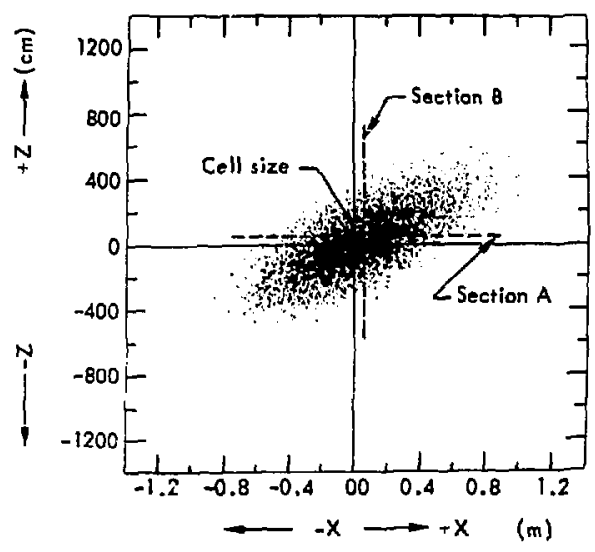

Fig. 1. Distortion of an initially spherical Gaussian puff under simple ahear in the $X-Z$ plane.

Lagrangian-Eulerian scheme: it eliminates the fictitious diffusion inherent in a purely Eulerian method of calculating transport and diffusion. This is largely accomplished by using a suitable algorithm for the diffusive transport.

Our future research plans for ADPIC include developing the code to incorporate scavenging, transformation, and depesition processes and applying the code to detailed regional cases.

\section{ATMOSPHERIC MASS-CONSISTENT WIND FIELD MODEL}

In the past year several significant improvements have been made in massconsistent wind field modeling. Special emphasis has been placed on the description of the time- and space-dependent wind fields in the mixed layer of the San Francisco Bay Area, a topographically complex region. Modern techniques of optimization have been used for determining the advective fluxes on cell faces

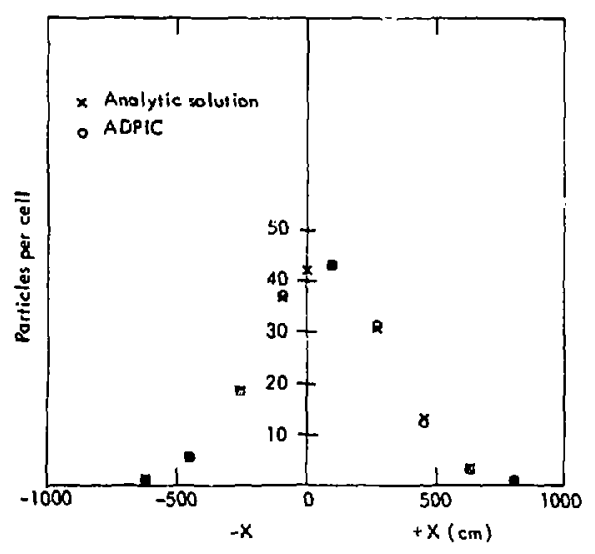

Fig. 2. Section A of Fig. 1 (X-Z plane, $\pm X$ direction) showing particle concentration per cell.

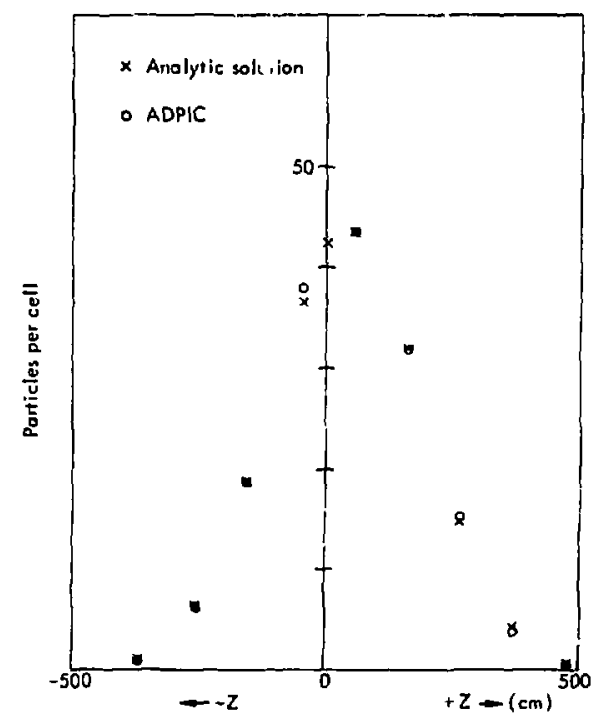

Fig. 3. Section B of Fig. 1 (X-Z plane, $\pm Z$ direction) showing particle concentration per :ell.

in our air pollution simulation rodel and for specifying wind fields for ALIPIC. 
The purpose of the mass-consistent wind field submodel is to

- calculate a flow field that is consistent with the kinematic boundary conditinis of the earth's surface

- match the time and space history of the inversion surface frequently topping the mixed layer

- meet the requirement of conservation of nass in three dimensions

- fit the observed wind data from NWS stations or other auxiliary stations that are available in the San Francisco Bay Arez. 10

Figure 4 shows interpolated and unadjusted advective fluxes that have errors of interpolation or other unspecified errors. Because of the lack of threedimensional mass consistency, these errors can lead to a false increase or decrease in the concentration of a pollutant within a cell by a factor of 10 in a 3-hr period. The adjusted fluxes (Fig. 5),

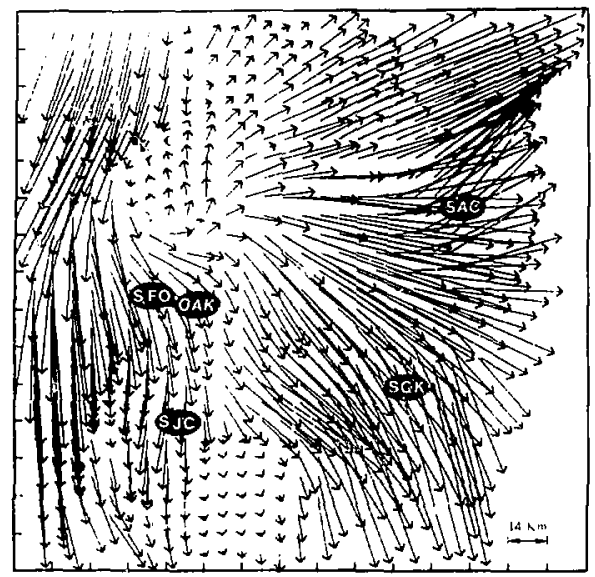

Fig. 4. Interpolated observations of surface velocity for 1330 PST, July 10, 1968 for the San Francisco Bay Area. obtained from the mass-consistent wind field submodel, reduce this error to approximateiy $10 \%$.

The mass-consistent wind field can be used as an input to air pollution and transport-diffusion models. The former involve time- and space-variable area solirces while the latter treat instantaneous or continuous emissions from a point source (e.g., ADPIC). The wind field prescribed by this submodel can also be used as an engineering aid in physically distorting the Gaussian plume solutions within a complex region. Useful solutions are thereby obtained that might. otherwise not be available.

\section{MULTIBOX REGIONAL AIR POLLUTION MODEL}

In the past two years, we have been developing numerical simulation models of air pollution oriented toward land use plan assessment. Specifically, we have

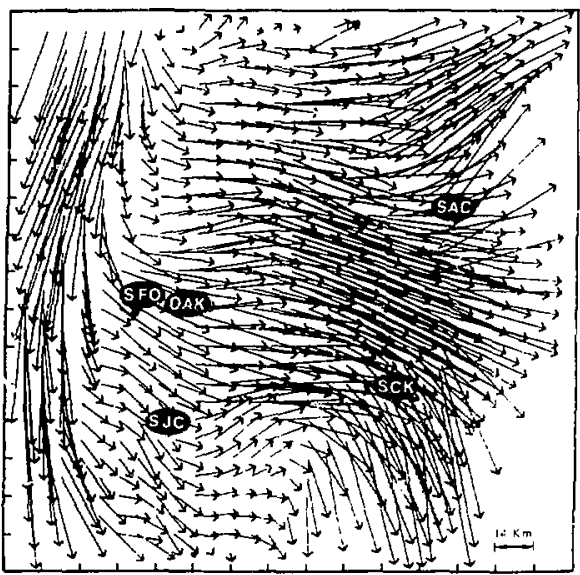

Fig. 5. Weak-constraint adjusted values of surface velocity for 1330 PST, July 10, 1968 for the San Francisco Bay Area. 
developed and initially verified an air pollution model for the San Francisco Bay Area. ${ }^{11,1}$ ? This model uses historical meteorological data to calculate the mean and surface air concentration in each riorlel cell. These concentrations 3acikuls tise erfecta of transport and diffu-

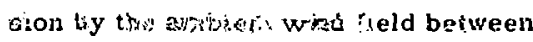
the irregular eartirts fursuge ard the

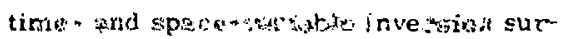
iface. The adyertive fuys on the sides. of the cells are cullulated by a massconsistent wind fietd is wodel, $8 \mathrm{~s}$ discussed previously. The model utilizes the mass-consistent wind field subrodet and muders terhniques for sciving the coupled sef of ordisary differential equiztions that fritern the evolution of pinoteshemical poliution.

$A$ verificiston case study for $\mathrm{CO}$ was carries out ka 549 hr test period during buly 596 ?. Figure 6 showe the ohberved houri: suerage concentration ot CO (ppins during the case study, ae well as tze compuied verical average and surface zverage huurly CO concertration. There is reasonable agreement hotween.

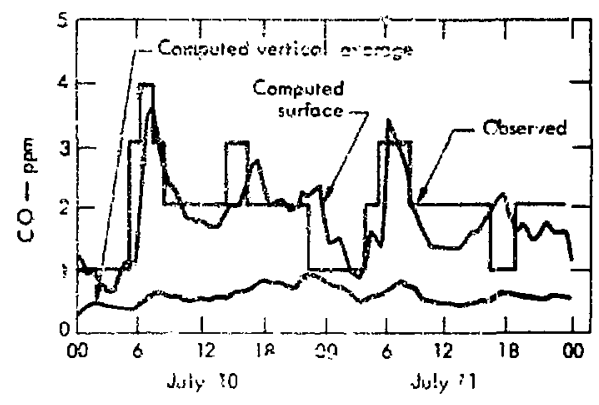

Fig. 5. Carbon monoxide concentrations for San Francisco, July 10-11, 1968.

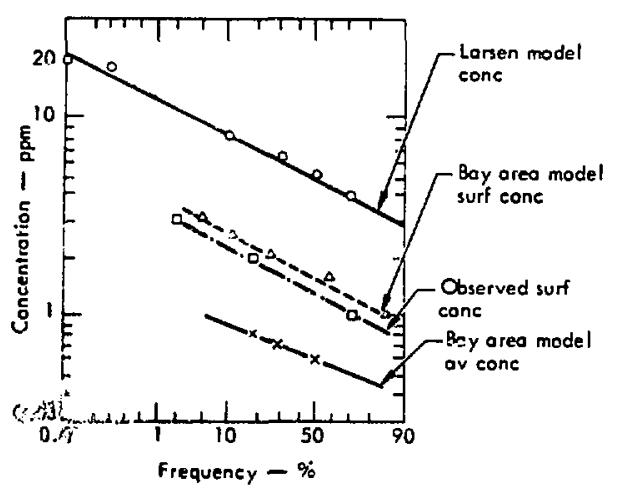

Fig. 7. Frequency dist: ibution of carbon rnonoxide concentration for San Francisco.

the o'sserved and calculated concentrations. These concentrations can also be displayed as a lognormal frequency distribution (Fig. 7). Note that the calculated frequency distribution for CO parallels the observed frequency distribution.

F. A. Giffor ${ }^{13}$ has recently noted that several numerical simulation models under development render numerical solutions that are noisier than the observed distributions. In general, a numerical solution contaminated with noise will not be able to predict the frequency distribution of the surface pollutant. Therefore, comparisons of predicted frequency distributions to ambient air quality standards may be severely limited.

Hence one criterion for an acceptable numerical simulation of air pollution is that the model be able to reproduce the frequency distribution characteristics of the pollutants involved in the region of interest. ${ }^{14}$ Although the testing of our air pollution model is still limited at the present time, it appears that, at least on the first test, this criterion has been met. 


\section{Transferable Experience Illustrated for Sediment Transport}

Atmospheric modeling investigators and numerical hydrodynamicists have been examining the sediment transport problem. We have identified a clear and strategic need for two separate attacks on the problem:

- the fate of dredge spoils released into transient stratified shear flow within an estuarine channel selected as a potential spoil disposaJ. site must be determined in three dimensions. A close-in solution in the immediate vicinity of the ciisposal site is required.

- a three-dimensional sediment transport model that can be applied to complex estuarine systems (such as the San Francisco Bay) for reasonably extended periods of integration must be developed. The fate of natural and man-made sediment loads must be determined on a regional scale.

For both of the above tasks, we will first describe the physical scenario to be simulated, and then discuss the elements of our experience that, when appropriately utilized, form a basis for system simulation.

SMALL-SCALE MODELING OF DREDGE SPOIL DISPOSAL

Dredge spoils, when transported to a site of disposal, constitute a slurry having a density of the order of 1.1 to $1.7 \mathrm{~g} / \mathrm{cc}$. When the spoils are released into a stratified or partially mixed estuary, the density of the released material exceeds that of the ambient flow into which the material is released. By vir- tue of this density anomaly, once the spoils material is waterborne, the fluid containing the spoil has a negative buoyancy, or if viewed in another way, the new hydrostatic pressure that exists will set up an induced circulation which transports and dilutes the spoii. This initial dilution may occur in either the fresher waters near the estuary surface or in the more saline waters further beneath the surface. During transport by the induced circulation, the spoils are also transported by the ambient flow field. Once the negative buoyancy is small in comparison to density variations resulting from salinity, the material is transported by the regional flow field alone and becomes subject to flocculation or other transformation processes. The flocculated and complex sediment component is subject to preferential deposition in regions of slow or stagnant flow within the estuarine system.

It is proposed that the Eulerian grid version of ADPIC be adapted to simulate this system. The initial volume and density of the released material can be represented by several thousand particles whose integrated mass is equal to the mass of the released material. Several particle sizes nay be used if this is required to adequately describe the material. To ascertain the pressure field resulting from sediment loading alone, the hydrostatic equation will be solved in the vertical by integrating from the bottom depth (which can be variable in the horizontal plane) to the free surface, neglecting salinity. The induced circulation and the resulting transport velocity for 
each of the Lagrangian particles will be calculated. The transport velocity for each of the particles resulting from the regional flow field will also be specified. At this point the regional flow field is assumed to be known from field measurements, measurements in a physical model, estimates from a mass-consistent flow model adapted to aquatic systems, or from a regional hydrodynamic model. As was illustrated for the atmospheric case, the diffusive velocity of each Lagrangian particle can be estimated from the concentration gradient and a diffusivity tensor reasonably prescribed in space and time. For each particle, these transport velocities (induced circulation, regional flow field, and diffusive) will be summed vectorially and a new position of each particle will be determined from the velocity vector and the calculational time step. If transformation or deposition should occur during the time step, material budgets will be modified at this point, and unit area deposition increments will be calculated and stored. The result of this sequence of operations is the establishment of a new initial condition. The logical loop discribed above will then be repeated for numerous calculational time steps until either a density anomaly test is satisfied or the material is completely deposited.

Sensitivity studies may include examining the effects of

- initial conditions such as the volume a. - density of the spoils

- uncertainties in the prescription of the diffusivity tensor in terms of the bulk dependent variables of the flow

- selecting different stages of the tidal cycle for disposal or the most favorable time for disposal

- selecting different locations as disposal sites.

\section{REGIONAL-SCALE MODELING OF SEDIMENT TRANSPORT}

In contrast to the small-scale transport discussed in the previous section, regionalscale sediment transport depends on the general properties of the entire estuarine system. Consider a large estuary in which, because of the presence of tidal control, the mean flow through the system is generally small compared to the integrated mass flux. The system is heterogeneous, varying from well mixed in the shallow area to stratified near river mouths that enter the estuary. The sediment load has two principal natural components: one from the streams, particularly during periods of high flow, and a second from wind-generated aquatic turbulence operative especially in shallow areas. Within this estuarine system there may well be points of accumulation which require periodic dredging; understanding the sediment mass budget of such areas leads to the most effective engineering solutions. The degree to which the natural sediment sourcers contribute to these accumulation subregions is generally not known.

The estuarine system has three gelleral layers of flow: (1) an underlying saline layer of oceanic origin, (2) a fresh water layer extending from the river mouths, and (3) a wind driven upper layer. Internal pressure fields leading to threedimensional circulations $a-i s e$ from salinity differences, from free surface anomalies resulting from wind stress, and 


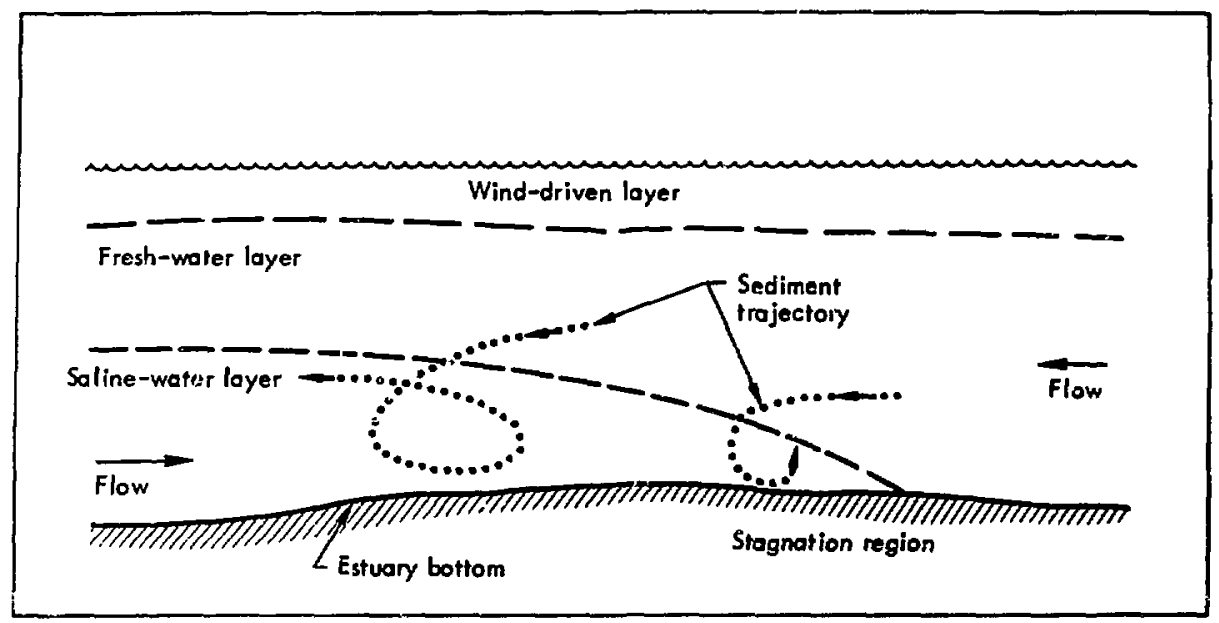

Fig. 8. Schematic vertical section along an estuarine channel.

from eddy transfers of momentum in shear flow. Figure 8 shows a schematic illustration of these zones at an early stage of flood tide. Note that streamborne sediment which is mixed down into the saline layer can be subjected to transnort by the mixing-induced circulation in the saline water. While in this induced circulation, flocculation can occur leading to deposition near the stagnation point (Fig. 8). This illustrates one type of accumulation point in an estuarine system; others exist conceptually without such strong dependence on threedimensional processes.

The following procedure is proposed to simulate this system. For a given period of interest and for a specified estuarine system, it is assumed that stream inflows, sediment burdens, temperature, tidal stage at entrance, surface wind stress, and bathimetry are known. In addition to the physical laws stated below, the sources of sediment resulting from aquatic turbulence, the horizontal and vertical eddy diffusivities as a function of the bulk dependent variables of the now, and criteria for the rates of nocculation and deposition must also be prescribed. The volume of the system can be suitably zoned into fixed Eulerian boxes whose shapes will be largely determined by the bathimetry. The hydrodynamic behavior of the system will be numerically simulated using the equations for conaervation of momentum, mass, salinity, internal energy, and conservation of one or more sediment types, aiong with a suitable equation of state wherein density is a function of temperature and salinity alone. These physical principles. when stated as partial differential equations, can be transformed into ordinary differential equations by Stokes theorem, algebric manipulation, and volume integration for the selected zoning. This has been done for the San Francisco Bay Area air pollution model. It is suggested that 
the Laboratory-modifled Gear Method, ${ }^{15}$ which hats been used for atmospheric pollution problems, be applied to carry out the long-term integration of the resulting set of ordinary differential equations.

When the feasibility of performing aquatic simulations for multiple tidal cycles has been demonstrated, specific applications of the regional sediment transport model could then be planned.
Validation may include

- mapping a sediment tracer in a real system by means of a field sampling experiment and comparing the field measurements to the simulation

- comparing the general features of calculated advective fluxes with those features derived from one of the Corps of Engineers' physical models (e.g., the San Francisco Bay Physical Model).

\section{Concluding Remarks}

Water quality properties are associated with definitive national environmental needs. Our study team has identified two strategic modeling tasks in regard to regional sediment transport. The Lawrence Livermore Laboratory, because of recently developed methods for treating analogous atmospheric problems, appears to be in a unique position to address these stated aquatic needs. It is anticipated that the need for full scale validation studies will emerge as our research evolves, and that the participation of several disciplinary investigators or agencits may be desirable. It should be noted that the simulation of environmental pollution, by whatever method, is today strongly affected by the quality of available source term information and present knowledge of important physical and environmental processes: the numerical simulation of aquatic systems is no exception in this regard. 


\section{References}

1. W. Garcia, A Study of Water Waves Generated by Tectonic Displacements, University of California, Berkeley, Hydraulic Engineering Laboratory, Rept. HEL $16 \cdot 9$, (1972).

2. J. B. Knox, Movement and Dispersion of Ion Species Through Porous Media, Lawrence Livermore Laboratory, Rept. UCRL-7997 (1964).

3. J. A. Korver, The OGRE Code - . Two Dimensional Numerical Model of the Transient Flow of One or Two Compressible Fluids Through Confined Poroug Media, Lawrence Livermore Laboratory, Rept. UCRL-50B20 (1970).

4. T. V. Crawford, Lawrence Livermore Laboratory, private communication (February 1969).

5. A. Okubo and D. W. Pritchard, Sumnary of our Present Knowledge of the Physical Processes of Mixing in the Ocean and Coastal Water, and a Set of Practical Guidelines for the Application of Existing Diffusion Equations in the Preparation of Nuclear Safety Evaluations of the Use of Nuclear Power Sources in the Sea. (Chesapeake Bay Institute, The John Hopkins University, September 1969).

6. J. B. Knox, D. E. Rawson, and J. A. Korver, J. Geophysical Rea. 70, 823 (1965).

7. J. B. Knox, Numerical Modeling of the Transport, Diffusion, and Deposition of Pollutants for Regions and Extended Scales, Lawrence Livermore Laboratory, Rept. UCRL-74666 (973).

8. W. K. Crandall, C. R. Molenkamp, A. L. Williams, M. M. Fulk, R. Lange, and J. B. Knox, An Investigation of Scavenging of Radioactivity from Nuclear Debris Clouds: Research in Progress, Lawrence Livermore Laboratory, Rept. UCRL51328 (1973).

9. A.F. Quesada, Some Solutions of the Differential Equation for an Expanding Gas Cloud in a Constant Shear Flow, A FCRL, Physical Sciences Research Report, No. 446 (Feb. 1971 ).

10. M. H. Dickerson, Summary of Research Related to Mass Consistent Wind Field Analysis for the San Francisco Bay Area, Lawrence Livermore Laboratory, Rept. UCRL-74265 (1972).

11. M. C. MacCracken. T. V. Crawford, K. R. Peterson, and J. B. Knox, Development of a sulti-Box Air Pollution Model and Initial Verification for the San Francisco Ba Area, Lawrence Livermore Laboratory, Rept. UCRL-73348 (1971).

12. M.C. MacCracken, T.V. Crawford, K. R. Peterson, and J.B. Knox, Initial. Application of a Multi-Box Air Pollution Model to the San Francisco Bay Area, Lawrence Livermore Laouratory, Rept. UCRL-73944 (1972).

13. F.A. Gifford, National Oceanic and Atmospheric Administration, private communication (February 1973)

14. J. B. Knox, Atmospheric Modeling and Environmental Protection Needs, Lawrence Livermore Laboratory, Rept. UCRL-74249 (1972).

15. R.J. Gelinas, J. of Computational Physics 9 (1972). 